\title{
Effects of dietary levels of tapioca residue on growth performance and carcass characteristics in Hanwoo steers
}

\author{
Byung Ki Park ${ }^{1, a}$, Dong Kyo Lee, ${ }^{1, a}$, Jun Sang Ahn², Joong Kook Park ${ }^{1}$, Min Ji Kim³, \\ Gi Hwal Son ${ }^{3}$, and Jong Suh Shin ${ }^{3, *}$
}

\begin{abstract}
* Corresponding Author: Jong Suh Shin Tel: +82-33-250-8697, Fax: +82-33-255-4037 E-mail: jsshin@Kangwon.ac.kr
\end{abstract}

${ }^{1}$ Nonghyup Feed Co., LTD, Seoul 05398, Korea 2 Hanwoo Research Institute, National Institute of Animal Science, RDA, Pyeongchang 25340, Korea

${ }^{3}$ College of Animal Life Sciences, Kangwon National

University, Chuncheon 24341, Korea

a These authors contributed equally to this work.

ORCID

Byung Ki Park

https://orcid.org/0000-0001-5469-2012

Dong Kyo Lee

https://orcid.org/0000-0001-7711-2316

Jun Sang Ahn

https://orcid.org/0000-0001-7362-9270

Joong Kook Park

https://orcid.org/0000-0002-9959-0578

Min Ji Kim

https://orcid.org/0000-0001-6485-1718

Gi Hwal Son

https://orcid.org/0000-0001-6406-0262

Jong Suh Shin

https://orcid.org/0000-0003-1148-2562

Submitted Oct 8, 2018; Revised Nov 1, 2018; Accepted Dec 27, 2018
Objective: This study was conducted to investigate the effects of dietary levels of tapioca residue on growth performance, carcass characteristics, and meat composition in Hanwoo steers.

Methods: Twenty-eight steers were randomly assigned to one of four dietary groups; T0 ( $0 \%$ tapioca residue), T6.7 (6.7\% tapioca residue), T9 (9\% tapioca residue), and T12 (12\% tapioca residue).

Results: Supplementation with tapioca residue had no effect on overall growth performance. The concentration of plasma total cholesterol was higher in T6.7 than in other treatments $(p<0.05)$. Dietary levels of tapioca residue did not affect carcass yield or the quality traits of Hanwoo steers. The lightness, redness, and yellowness of the longissimus muscle of Hanwoo steers were higher in T6.7 than in other treatments $(\mathrm{p}<0.05)$. Cohesiveness, gumminess, chewiness, and resilience were lower in T6.7 than in other treatments $(\mathrm{p}<0.05)$.

Conclusion: The results of the present study indicate that supplementation with tapioca residue does not exert any negative effects on growth performance, carcass characteristics, and meat composition in Hanwoo steers. However, as the dietary level of tapioca residue increased, the intake of concentrate intake decreased, and tapioca supplementation greater than $6.7 \%$ did not substantially improved the marbling score.

Keywords: Blood Metabolite; Growth Performance; Hanwoo Steers; Meat Composition; Tapioca Residue

\section{INTRODUCTION}

In 2016, the production of concentrates for beef cattle was 4.5 million tons in Korea and reflects a steadily increasing trend in recent years. As corn is the most commonly used feed in concentrate formulations, corn imports have been steadily increasing [1]. In Korea, feed costs account for more than $60 \%$ of the total production cost of cattle, which increase concomitantly with increases in the usage rate of corn.

Tapioca which costs a mere $60 \%$ to $70 \%$ of the cost of corn can replace some of the energy (carbohydrates) of enriched raw materials, such as corn and wheat. As the nutrient content of tapioca (especially in terms of starch) is similar to that of corn, it is a valuable substitute for corn [2]. Despite this, the usage rate of tapioca for beef cattle feed remains between $2 \%$ and $4 \%$ in Korea.

It has been shown that replacing $30 \%$ of total corn usage with tapioca in growing pigs does not affect their productivity [3]. Furthermore, Enriquez and Ross [4] reported that replacing $50 \%$ of total corn usage with tapioca does not affect mortality, laying ability, and egg quality in laying hens. 
In ruminants, the digestibility of tapioca is higher than that of sorghum and is similar to that of corn flakes [2]. The digestibility of tapioca starch in the rumen, small intestine, and colon were $94 \%, 5 \%$, and $1 \%$, respectively [5]. Muller et al [6] reported that tapioca starch was more digestible than general grains, but that it also required the addition of a nitrogen source for ruminal microbial protein synthesis owing to its low protein content $(2.3 \%$ to $2.5 \%)$.

While previous studies $[2,7]$ have been limited to the alternative status of tapioca in comparison to grains (corn, barley, oats, etc.), there have been few studies on the effects of tapioca residue supplementation on feed intake, growth performance, carcass characteristics, and meat quality in beef cattle. In particular, to the best of our knowledge, no studies have investigated changes in performance in response to dietary levels of tapioca residue in Hanwoo steers.

Therefore, the aim of this study was to investigate the effects of dietary levels of tapioca residue on growth performance, blood metabolites, carcass characteristics, and meat composition in the late fattening stages of Hanwoo steers.

\section{MATERIALS AND METHODS}

The steers used in the present study were managed according to the scientific guidelines of the Animal Experiment Ethics Committee of Kangwon National University (No: KIACUC16-0010).

\section{Animals, treatments, and management}

Twenty-eight Hanwoo steers (mean weight $619.8 \pm 63.8 \mathrm{~kg}$, approximately 24 months of age) were randomly assigned to any one of four dietary treatments: T0 ( $0 \%$ tapioca residue), T6.7 (6.7\% tapioca residue), T9 (9\% tapioca residue), and T12 (12\% tapioca residue). Steers were allotted by treatment group into four pens $(5 \times 10 \mathrm{~m})$, each covered with $20 \mathrm{~cm}$ of sawdust.

Concentrate was provided three times daily $(08: 30,13: 00$, and 17:00) using an automatic feeding system (SEOCHANG $65 \mathrm{M} / \mathrm{M}$, Seochang Co., Ltd., Cheonan, Korea) at approximately $1.8 \%$ of body weight (BW, as-fed basis) for the entire experimental period. Rice straw (dry matter $90.18 \%$, crude protein $3.65 \%$, ether extract $1.02 \%$, crude fiber $34.19 \%$, neutral detergent fiber $70.21 \%$, acid detergent fiber $38.13 \%$, crude ash $10.58 \%$, calcium $(\mathrm{Ca}) 0.09 \%$, and phosphorus $[\mathrm{P}] 0.05 \%)$ and water could be accessed freely. The formula percentages and nutrient contents of the concentrates are presented in Table 1. The chemical compositions of the experimental diets were analyzed by the standard methods of the AOAC [8].

\section{Feed intake, body weight, and blood characteristics}

The average daily gain (ADG) was calculated by measuring BW at 10 am every 2 months. Feed intake was measured daily by measuring the leftover feed still present before the morn-
Table 1. Ingredient and chemical compositions of the experimental diets of Hanwoo steers

\begin{tabular}{lcccc}
\hline \multirow{2}{*}{ Item } & \multicolumn{4}{c}{ Treatments } \\
\cline { 2 - 5 } & T0 & T6.7 & T9.0 & T12.0 \\
\hline \multirow{2}{*}{ Corn grain } & -------- lngredient composition (\%) & --------- \\
Wheat grain & 37.9 & 34.0 & 34.1 & 34.0 \\
Cane molasses & 10.0 & 10.0 & 10.0 & 10.0 \\
Wheat flour & 5.0 & 5.0 & 5.0 & 5.0 \\
Tapioca residue & 2.0 & 2.0 & 2.0 & 2.0 \\
Soybean meal & - & 6.7 & 9.0 & 12.0 \\
Wheat bran & - & - & - & 2.0 \\
Corn gluten feed & 5.6 & 1.0 & 1.0 & 1.0 \\
Rapeseed meal & 20.0 & 20.0 & 17.1 & 11.7 \\
Palm kernel meal & 2.2 & 3.7 & 5.0 & 5.0 \\
Lupin & 9.0 & 9.0 & 6.0 & 6.0 \\
Rice polishing & 2.5 & 2.5 & 2.5 & 2.5 \\
Marblelist (feed additive) & 1.0 & 1.0 & 1.0 & 1.0 \\
Emulsifier & 1.0 & 1.0 & 1.0 & 1.0 \\
Vitamin premix) & 0.1 & 0.1 & 0.1 & 0.1 \\
Mineral premix & 0.1 & 0.1 & 0.1 & 0.1 \\
Sodium bicarbonate & 0.1 & 0.1 & 0.1 & 0.1 \\
& 0.5 & 0.5 & 0.5 & 0.5 \\
Dry matter & --------- & Chemical composition (\%) & ----------- \\
Crude protein & 88.30 & 88.23 & 88.14 & 87.98 \\
Ether extract & 12.21 & 12.23 & 12.18 & 12.26 \\
Crude fiber & 3.58 & 3.45 & 3.37 & 3.32 \\
Crude ash & 5.75 & 6.42 & 6.33 & 6.37 \\
Ca & 6.17 & 5.92 & 5.98 & 5.89 \\
P & 0.91 & 0.75 & 0.75 & 0.75 \\
TDN & 0.41 & 0.39 & 0.38 & 0.37 \\
\hline TDN & 73.44 & 74.12 & 73.80 & 73.67 \\
\hline
\end{tabular}

TDN, total digestible nutrients (calculated value).

1) Vitamin premix provided the following quantities of vitamins per kilogram of diet: vitamin A, 10,000 IU; vitamin $D_{3}, 1,500 \mathrm{IU}$; vitamin $\mathrm{E}, 25 \mathrm{IU}$.

${ }^{2)}$ Mineral premix provided the following quantities of minerals per kilogram of diet: Fe, 50 mg; Cu, 7mg; Zn, 30 mg; Mn, 24 mg; I, 0.6 mg; Co, 0.15 mg; Se, 0.15 mg.

ing feeding. The feed conversion ratio (FCR) was calculated using dry matter intake (DMI) and ADG.

Blood samples $(3 \mathrm{~mL})$ for the analyses of blood metabolites were taken at 2-month intervals from the jugular vein of experimental animals using an 18-gauge needle and a blood collection tube (Vacutainer, Becton-Dickinson, Franklin Lakes, NJ, USA) coated with heparin. In addition, $3 \mathrm{~mL}$ of blood for blood corpuscle analyses was collected in another blood collection tube containing ethylenediaminetetraacetate.

Blood samples were stored in an ice box and transferred to the laboratory within $6 \mathrm{~h}$ of collection.

Blood samples were centrifuged at $1,250 \times \mathrm{g}$ for $10 \mathrm{~min}$ to separate the plasma and analyzed using an automatic blood analyzer (Hitachi 7020, Hitachi Ltd., Tokyo, Japan). The analyses included glucose, total cholesterol (TC), albumin, total protein, triglyceride (TG), total bilirubin, blood urea nitrogen, gamma-glutamyl transpeptidase, glutamic oxaloacetic-trans- 
aminase, glutamic-pyruvic transaminase, non-esterified fatty acid (NEFA), creatinine, $\mathrm{Ca}, \mathrm{P}$, and magnesium $(\mathrm{Mg})$.

Samples for the analyses of blood corpuscles were transferred to the laboratory and mixed using a roller mixer (1580RMulti-purpose Centrifuge, LABOGENE, Bjarkesvej, Denmark). Red blood cell (RBC), red cell distribution width (RDW), reticulocytes (RETIC), white blood cell (WBC), hemoglobin (HGB), hematocrit (HCT), mean corpuscular volume (MCV), mean corpuscular hemoglobin $(\mathrm{MCH})$, mean corpuscular hemoglobin concentration (MCHC), neutrophil count (NEU), eosinophil count (EO), basophil count (BA), lymphocyte count (LYM), leucocyte count with monocyte (MONO), and platelet count (PLT) were analyzed using a hematology analyzer (ProCyte Dx, IDEXX laboratories Inc., Westbrook, ME, USA).

\section{Carcass characteristics and meat composition of longissimus muscle}

At the end of the experimental period (30 months of age), all animals were slaughtered at the local slaughterhouse to assess carcass yield and quality traits. Carcass evaluation was performed at the 13th rib section from the left side of each carcass by meat graders using the criteria provided by the Korean carcass grading system [9]. Meat quality traits were measured for marbling score, meat color, fat color, texture, and maturity. Yield traits were measured for carcass weight, back fat thickness, and rib eye area. The carcass yield index (YI) was calculated according to the following equation: $\mathrm{YI}=(68.184-$ $[0.625 \times$ back fat thickness $\{\mathrm{mm}\}])+\left[0.130 \times\right.$ rib eye area $\left.\left\{\mathrm{cm}^{2}\right\}\right]-$ [0.024 $\times$ carcass weight $\{\mathrm{kg}\}])+3.23$.

The chemical compositions of the longissimus muscle were measured according to the standard methods of the AOAC [8]. To measure the $\mathrm{pH}$ of meat, approximately $10 \mathrm{~g}$ of longissimus muscle was cut into small pieces and homogenized with $90 \mathrm{~mL}$ of distilled water (PolyTron PT-2500 E, Kinematica, Lucerne, Switzerland). The $\mathrm{pH}$ values were measured immediately after homogenization using a pH meter (Orion 230A, Thermo Fisher Scientific Inc., Waltham, MA, USA).

For the measurement of cooking loss, $1.0 \mathrm{~cm}$-thick steaks were put in a polyethylene bag and heated in a water bath at $75^{\circ} \mathrm{C}$ for $40 \mathrm{~min}$, and subsequently cooled at room temperature for $30 \mathrm{~min}$. The percent cooking loss was determined by the difference in steak weights taken before and after cooking. Drip loss was measured as the weight loss during the suspension of a standardized $(2 \times 2 \times 1 \mathrm{~cm})$ sample sealed in a polyethylene bag at $4^{\circ} \mathrm{C}$ after 6 days of storage.

Water holding capacity (WHC) was measured according to the procedure of Hofmann and White [10]. Briefly, a $0.3 \mathrm{~g}$ sample of muscle was placed in a filter-press device and compressed for $5 \mathrm{~min}$. After this process, WHC was calculated from duplicate samples as the ratio of the meat film area to the total area using an area-line meter (Super PLANIX-a, Tamaya Technics Inc., Tokyo, Japan).
Shear force values were determined using a Texture Analyzer (TA 1, LLOYD instruments LTD., Fareham, UK) with the following operating parameters: load cell, $50 \mathrm{~kg}$; test and trigger speed, $50 \mathrm{~mm} / \mathrm{min}$; and trigger forces, $0.01 \mathrm{kgf}$.

Texture profile analyses were made by placing samples in a polyethylene bag and heating them to a constant temperature bath until the core temperature reached $75^{\circ} \mathrm{C}$. After forming each longissimus muscle sample to $1 \times 1 \times 1 \mathrm{~mm}$, the hardness, elasticity, cohesiveness, gumminess, and chewiness were measured using a texture analyzer equipped with a cylindrical probe of Ø35 mm (TA-XT plus, Stable Micro Systems Co., Ltd., London, UK). The samples were measured by pressing $80 \%$ of the sample height twice with pretest, test, and post-test speeds of $1 \mathrm{~mm} / \mathrm{s}$.

Meat color was measured using a colorimeter (Colormeter CR-300, Minolta Co., Osaka, Japan) immediately after removing the meat from the polyethylene bag. The color values of $\mathrm{L}^{*}$ (lightness), $\mathrm{a}^{*}$ (redness), and $\mathrm{b}^{*}$ (yellowness) were repeatedly measured in the same manner. The standard white plate had a $\mathrm{Y}$ value $=93.60$, an $\mathrm{x}$ value $=0.3134$, and a $\mathrm{y}$ value $=0.3194$.

The measurement of volatile basic nitrogen (VBN) was performed according to the method of Kim et al [11] using a Conway unit. Distilled water $(90 \mathrm{~mL})$ was added to longissimus muscle samples (10 g), was homogenized (PolyTron PT-2500 E, Kinematica, Switzerland), and subsequently centrifuged at $3,000 \times g$ for $10 \mathrm{~min}$. The supernatant was filtered using filter paper and $0.01 \mathrm{~N}$ boric acid $(1 \mathrm{~mL})$. An indicator $(0.066 \%$ methyl red:bromocresol green $=1: 1$ ) was added to the inner chamber of the Conway unit and the filtrate $(1 \mathrm{~mL})$, while $50 \%$ potassium carbonate $(1 \mathrm{~mL})$ was added to the outer chamber. The sealed Conway unit was maintained at $37^{\circ} \mathrm{C}$ for $2 \mathrm{~h}$. The samples were titrated against $0.01 \mathrm{~N}$ sulfuric acid. The concentration of VBN was calculated as ammonia equivalents using the following equation: $\mathrm{VBN}(\mathrm{mg} \%)=(\mathrm{A}-\mathrm{B}) \times \mathrm{F} \times 28.014$ $\times 100 / S$, where, $A$ is the total amount of sulfuric acid (titrate sample $[\mathrm{mL}]$ ), $B$ is the total amount of sulfuric acid (titrate blank sample $[\mathrm{mL}]), \mathrm{F}=0.02 \mathrm{~N}$ standard index of sulfuric acid, and $S$ is the sample weight $(10 \mathrm{~g})$.

The determination of 2-thiobarbituric acid reactive substances (TBARS) in the longissimus muscle was performed according to the methods of Witte et al [12]. Briefly, each sample ( $10 \mathrm{~g}$ ) was added to $25 \mathrm{~mL}$ of $20 \%$ trichloroacetic acid (in $2 \mathrm{M}$ phosphoric acid) and homogenized for $30 \mathrm{~s}$. The samples were diluted with distilled water until the total amount of the homogenate was $50 \mathrm{~mL}$ and were then centrifuged $(3,000 \times g$, $4^{\circ} \mathrm{C}, 10 \mathrm{~min}$ ). After centrifugation, the supernatant was filtered using filter paper and five milliliters of $0.005 \mathrm{mM}$ TBARS was added to the filtrate $(5 \mathrm{~mL})$ and allowed to stand at room temperature for $15 \mathrm{~h}$. The absorbance of the solution was measured at $530 \mathrm{~nm}$ using a UV/VIS spectrophotometer (M2e, Molecular Devices, Sunnyvale, CA, USA). TBARS was calculated according to the following equation: TBARS 
( $\mathrm{mg}$ of malondialdehyde/kg of sample) $=$ (optical density [OD] of sample - OD of blank sample) $\times 5.2$.

\section{Statistical analyses}

The least squares method was used to estimate the environmental effects on BW, ADG, blood characteristics, and carcass traits. The following linear model was used: $\mathrm{y}_{\mathrm{ijkl}}=\mu+\mathrm{TRT}_{\mathrm{i}}+$ $\beta_{1} X_{1 i j}+\beta_{2} X_{2 i k}+e_{i j k l}$, where $\mu=$ overall average; $T_{R T}=$ treatment effect $(1-4) ; X_{1}, X_{2}=$ the covariation of castration age and measurement month; $\beta_{1}, \beta_{2}=$ regression coefficient, and $\mathrm{e}_{\mathrm{ikkl}}$ $=$ random error effect.

The least squares method was also used to estimate environmental effects on feed intake and FCR. The following linear model was used: $\mathrm{y}_{\mathrm{ij}}=\mu+\mathrm{TRT}_{\mathrm{i}}+\mathrm{e}_{\mathrm{ij}}$, where $\mu=$ overall average, $\mathrm{TRT}_{\mathrm{i}}=$ treatment effect $(1-4)$, and $\mathrm{e}_{\mathrm{ij}}=$ random error effect.

The linear model was analyzed using SAS 9.1 [13] The package and variance analysis was performed using a Type III squared fit for unbalanced data among the four squares presented in the SAS/GLM analysis. The statistical significance of the differences between the least squares averages of the treatments were tested with the following null hypothesis at a significance level of 5\%: Ho: lease squares means (LSM) (i) $=\operatorname{LSM}(j)$, where $\operatorname{LSM}(i(j))$ is the least squares average of the $I(j)$ effects $(I \neq j)$.

\section{RESULTS}

\section{Growth performance and blood characteristics}

The effects of the dietary level of tapioca residue on BW gain, feed intake, and FCR of late fattening Hanwoo steers are shown in Table 2. The difference in initial BWs between the highest and lowest groups was $10.86 \mathrm{~kg}$; however, this difference was
Table 2. Effects of dietary levels of tapioca residue on growth performance in late fattening Hanwoo steers

\begin{tabular}{|c|c|c|c|c|c|c|}
\hline \multirow{2}{*}{ Item } & \multicolumn{4}{|c|}{ Treatments } & \multirow{2}{*}{ SEM } & \multirow{2}{*}{$\operatorname{Pr}>\mathrm{F}$} \\
\hline & TO & T6.7 & T9.0 & $\mathrm{T} 12.0$ & & \\
\hline \multicolumn{7}{|l|}{ Body weight (kg) } \\
\hline Initial BW & 621.14 & 615.43 & 626.29 & 616.43 & 25.52 & 0.99 \\
\hline Final BW & 744.29 & 748.57 & 744.29 & 734.14 & 31.05 & 0.99 \\
\hline Average daily gain & 0.68 & 0.74 & 0.65 & 0.65 & 0.01 & 0.73 \\
\hline \multicolumn{7}{|l|}{ Intake (DM, kg) } \\
\hline Concentrate & 10.31 & 10.17 & 9.63 & 9.56 & 0.46 & 0.85 \\
\hline Rice straw & 1.00 & 1.00 & 0.72 & 1.00 & 0.16 & 0.96 \\
\hline Dry matter & 11.31 & 11.17 & 10.35 & 10.56 & 0.53 & 0.78 \\
\hline Feed conversion ratio & 16.63 & 15.10 & 15.92 & 16.25 & 1.22 & 0.92 \\
\hline
\end{tabular}

SEM, standard error of mean; BW, body weight; DM, dry matter.

not statistically significant. The final BWs and ADG values were slightly but not significantly higher in T6.7 than in the other treatments.

The concentrate intake and DMI tended to decrease with increasing dietary levels of tapioca residue. The FCR was slightly but not significantly lower in T6.7 than in the other treatments.

The effects of the dietary level of tapioca residue on blood metabolites and blood corpuscles in late fattening Hanwoo steers are shown in Tables 3 and 4. The concentration of TC was higher in T6.7 than in the other treatments $(\mathrm{p}<0.05)$. The concentration of TGs was the lowest in T6.7, while the highest concentration was found in T12 $(\mathrm{p}<0.05)$. The concentration of Mg was the lowest in T12 ( $<<0.05)$, while the concentrations observed in other treatment groups was similar. The concentration of NEFA was higher in T9 than in T0 and T6.7 $(\mathrm{p}<0.05)$. Supplementation with tapioca residue exerted no

Table 3. Effects of dietary levels of tapioca residue on blood metabolites in late fattening Hanwoo steers

\begin{tabular}{|c|c|c|c|c|c|c|}
\hline \multirow{2}{*}{ Item } & \multicolumn{4}{|c|}{ Treatments } & \multirow{2}{*}{ SEM } & \multirow{2}{*}{$\operatorname{Pr}>\mathrm{F}$} \\
\hline & TO & T6.7 & T9.0 & T12.0 & & \\
\hline Total protein (g/dL) & 7.40 & 7.43 & 7.21 & 7.43 & 0.12 & 0.45 \\
\hline Albumin (g/dL) & 3.91 & 3.90 & 3.90 & 3.77 & 0.05 & 0.18 \\
\hline Total bilirubin (mg/dL) & 0.59 & 0.54 & 0.59 & 0.47 & 0.05 & 0.39 \\
\hline AST (IU/L) & 75.51 & 72.04 & 73.03 & 67.81 & 3.81 & 0.56 \\
\hline ALT (IU/L) & 21.50 & 21.10 & 19.73 & 19.09 & 0.94 & 0.25 \\
\hline $\mathrm{Ca}(\mathrm{mg} / \mathrm{dL})$ & 9.66 & 9.59 & 9.59 & 9.30 & 0.13 & 0.25 \\
\hline $\mathrm{GGT}(\mathrm{mg} / \mathrm{dL})$ & 29.27 & 23.50 & 24.69 & 33.96 & 3.58 & 0.18 \\
\hline Glucose (mg/dL) & 55.97 & 56.59 & 55.17 & 56.19 & 1.42 & 0.91 \\
\hline Cholesterol (mg/dL) & $124.57^{b}$ & $158.06^{\mathrm{a}}$ & $130.84^{b}$ & $119.39^{b}$ & 7.72 & 0.01 \\
\hline Phosphorus (mg/dL) & 6.96 & 6.83 & 6.89 & 6.79 & 0.18 & 0.92 \\
\hline BUN (mg/dL) & 15.63 & 15.53 & 16.34 & 14.26 & 0.63 & 0.16 \\
\hline Creatinine $(\mathrm{mg} / \mathrm{dL})$ & 1.29 & 1.27 & 1.40 & 1.33 & 0.39 & 0.12 \\
\hline NEFA (uEq/L) & $223.03^{b}$ & $219.59^{b}$ & $270.20^{a}$ & $237.86^{\mathrm{ab}}$ & 11.67 & 0.02 \\
\hline
\end{tabular}

SEM, standard error of mean; AST, aspartate aminotransferase; ALT, alanine aminotransferase; GGT, gamma glutamyl transferase; BUN, blood urea nitrogen; NEFA, non-esterified fatty acid.

${ }^{a, b}$ Mean values followed by different letters in the same row are significantly different $(p<0.05)$. 
Table 4. Effects of dietary levels of tapioca residue on blood corpuscle parameters in late fattening Hanwoo steers

\begin{tabular}{|c|c|c|c|c|c|c|}
\hline \multirow{2}{*}{ Item } & \multicolumn{4}{|c|}{ Treatments } & \multirow{2}{*}{ SEM } & \multirow{2}{*}{$\operatorname{Pr}>\mathrm{F}$} \\
\hline & TO & T6.7 & T9.0 & T12.0 & & \\
\hline $\mathrm{RBC}(\mathrm{M} / \mu \mathrm{L})$ & 7.83 & 8.04 & 7.78 & 7.32 & 0.21 & 0.14 \\
\hline HCT (\%) & 37.83 & 39.03 & 38.13 & 36.47 & 1.35 & 0.61 \\
\hline $\mathrm{HGB}(\mathrm{g} / \mathrm{dL})$ & 12.74 & 12.91 & 12.72 & 12.18 & 0.41 & 0.62 \\
\hline$M C V(f L)$ & 48.42 & 48.60 & 49.03 & 49.94 & 1.46 & 0.88 \\
\hline MCH (pg) & 16.29 & 16.10 & 16.35 & 16.70 & 0.42 & 0.78 \\
\hline $\mathrm{MCHC}(\mathrm{g} / \mathrm{dL})$ & 33.73 & 33.21 & 33.36 & 33.49 & 0.44 & 0.86 \\
\hline RDW (\%) & 29.08 & 29.64 & 28.38 & 27.19 & 0.77 & 0.16 \\
\hline RETIC (\%) & 6.90 & 7.29 & 7.34 & 6.84 & 0.63 & 0.92 \\
\hline WBC $(K / \mu L)$ & 9.11 & 9.63 & 9.11 & 8.73 & 0.53 & 0.69 \\
\hline NEU $(K / \mu L)$ & 3.02 & 2.94 & 2.67 & 2.91 & 0.23 & 0.72 \\
\hline 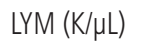 & 4.70 & 5.16 & 5.18 & 4.41 & 0.33 & 0.31 \\
\hline 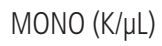 & 0.47 & 0.46 & 0.39 & 0.44 & 0.03 & 0.45 \\
\hline EOS $(K / \mu L)$ & 0.83 & 1.06 & 0.85 & 1.03 & 0.12 & 0.41 \\
\hline BASO $(\mathrm{K} / \mu \mathrm{L})$ & 0.03 & 0.02 & 0.02 & 0.02 & 0.01 & 0.26 \\
\hline PLT $(\mathrm{K} / \mu \mathrm{L})$ & 214.60 & 188.79 & 190.81 & 213.67 & 17.22 & 0.58 \\
\hline
\end{tabular}

SEM, standard error of mean; RBC, red blood cell; HCT, hematocrit; HGB, hemoglobin; MCV, mean corpuscular volume; MCH, mean corpuscular haemoglobin; $\mathrm{MCHC}$, mean corpuscular hemoglobin concentration; $\mathrm{RDW}$, red cell distribution width; RETIC, reticulocytes; WBC, white blood cell; NEU, neutrophil; LYM, lymphocyte count; MONO, monocyte; EOS, eosinophil; BASO, basophil; PLT, platelet count.

effects on RBC, HCT, HGB, MCV, MCHC, RDW, RETIC, WBC, NEU, LYM, MONO, EO, BA, and PLT in late fattening Hanwoo steers.

\section{Carcass characteristics and meat composition of the longissimus muscle}

The effects of the dietary level of tapioca residue on carcass characteristics in Hanwoo steers are shown in Table 5. The dietary level of tapioca residue did not affect carcass weight, back fat thickness, rib eye area, or yield index in Hanwoo steers. Furthermore, the dietary level of tapioca residue did not affect meat color, fat color, texture, or the maturity of Hanwoo steers. The marbling score was slightly but not significantly higher in T6.7 than in other treatments. Meat color and maturity were similar between the treatments.

The effects of the dietary level of tapioca residue on the meat composition in the longissimus muscle of Hanwoo steers are shown in Table 6 . The content of ether extract in the longissimus muscle was slightly but not significantly higher in T6.7, T9.0, and T12 than in T0. The dietary level of tapioca residue did not affect the content of crude protein or the $\mathrm{pH}$ value of the longissimus muscle of Hanwoo steers. The lightness, redness $(\mathrm{p}<0.05)$, and yellowness $(\mathrm{p}<0.05)$ of the longissimus muscle of Hanwoo steers were higher in T6.7 than in other treatments. The content of VBN tended to increase with increasing dietary levels of tapioca residue; however, the differences were not statistically significant. Hardness, springiness, cohesiveness, gumminess, chewiness, and resilience were lower in T6.7 than in other treatments $(\mathrm{p}<0.05)$.

\section{DISCUSSION}

\section{Growth performance and blood characteristics}

In the present study, although the difference was not statistically significant, concentrate intake decreased as the dietary level of tapioca residue increased during the late fattening period (Table 2). A similar finding was reported by Zinn and DePeters [7], wherein feed intake and efficiency were lower in the treatment group that received 30\% replacement than in the $15 \%$ replacement treatment group when replacing corn flakes with tapioca. In addition, Garcia and Dale [14] reported that palatability and feed intake tended to decrease as the di-

Table 5. Effects of dietary levels of tapioca residue on carcass characteristics in Hanwoo steers

\begin{tabular}{|c|c|c|c|c|c|c|}
\hline \multirow{2}{*}{ Item } & \multicolumn{4}{|c|}{ Treatments } & \multirow{2}{*}{ SEM } & \multirow{2}{*}{$\mathrm{Pr}>\mathrm{F}$} \\
\hline & TO & T6.7 & T9.0 & T12.0 & & \\
\hline \multicolumn{7}{|l|}{ Yield traits ${ }^{1)}$} \\
\hline Carcass weight $(\mathrm{kg})$ & 446.71 & 449.57 & 443.57 & 449.14 & 20.54 & 0.99 \\
\hline Back fat thickness (mm) & 14.29 & 14.29 & 12.71 & 14.57 & 1.84 & 0.89 \\
\hline Rib eye area $\left(\mathrm{cm}^{2}\right)$ & 91.00 & 93.57 & 90.71 & 92.43 & 2.52 & 0.84 \\
\hline Yield index & 63.59 & 63.86 & 64.61 & 63.54 & 1.24 & 0.92 \\
\hline \multicolumn{7}{|l|}{ Quality traits ${ }^{2)}$} \\
\hline Marbling score & 3.00 & 4.57 & 3.57 & 3.57 & 0.64 & 0.39 \\
\hline Meat color & 5.00 & 5.00 & 5.00 & 5.14 & 0.07 & 0.41 \\
\hline Texture & 1.86 & 1.29 & 1.43 & 1.71 & 0.18 & 0.13 \\
\hline Maturity & 2.00 & 2.00 & 2.00 & 2.00 & - & - \\
\hline
\end{tabular}

SEM, standard error of mean.

1) Area and back fat thickness were measured from the longissimus muscle taken at the 13th rib. Yield index was calculated using the following equation: (68.184 -

$[0.625 \times$ back fat thickness $\{\mathrm{mm}\}]+\left[0.130 \times\right.$ rib eye area $\left.\left\{\mathrm{cm}^{2}\right\}\right]-[0.024 \times$ dressed weight amount $\left.\{\mathrm{kg}\}]\right)+3.23$.

${ }^{2)}$ Grading ranges are 1 to 9 for marbling score, where higher numbers indicate better quality ( $1=$ devoid, $9=$ abundant); meat color $(1=$ bright red, $7=$ dark red); texture ( 1 = soft, 3 = firm); and maturity ( 1 = youthful, 9 = mature). 
Table 6. Effects of dietary levels of tapioca residue on meat composition in the longissimus muscles of Hanwoo steers

\begin{tabular}{|c|c|c|c|c|c|c|}
\hline \multirow{2}{*}{ Item } & \multicolumn{4}{|c|}{ Treatments } & \multirow{2}{*}{ SEM } & \multirow{2}{*}{$\operatorname{Pr}>\mathrm{F}$} \\
\hline & TO & T6.7 & T9.0 & T12.0 & & \\
\hline Moisture (\%) & 67.17 & 63.30 & 65.20 & 66.26 & 1.20 & 0.17 \\
\hline Ether extract (\%) & 11.47 & 17.03 & 14.34 & 14.38 & 1.60 & 0.15 \\
\hline Crude protein (\%) & 22.05 & 20.17 & 20.06 & 19.57 & 0.63 & 0.18 \\
\hline $\mathrm{pH}$ & 5.59 & 5.63 & 5.61 & 5.62 & 0.02 & 0.41 \\
\hline $\mathrm{CIE} \mathrm{L*}$ & 42.79 & 44.03 & 42.32 & 42.29 & 0.89 & 0.58 \\
\hline $\mathrm{CIE} \mathrm{a}^{*}$ & $20.77^{\mathrm{ab}}$ & $21.28^{\mathrm{a}}$ & $19.07^{c}$ & $19.19^{b c}$ & 0.53 & 0.02 \\
\hline $\mathrm{CIE} \mathrm{b*}$ & $10.38^{\mathrm{a}}$ & $10.81^{\mathrm{a}}$ & $9.34^{b}$ & $9.30^{b}$ & 0.30 & 0.01 \\
\hline Cooking loss (\%) & $31.26^{b}$ & $31.50^{\mathrm{ab}}$ & $30.70^{b}$ & $32.86^{\mathrm{a}}$ & 0.44 & 0.04 \\
\hline Drip loss (\%) & 6.52 & 6.39 & 4.98 & 5.52 & 0.51 & 0.15 \\
\hline WHC (\%) & 45.14 & 42.31 & 44.01 & 43.50 & 1.10 & 0.40 \\
\hline WBSF (kg) & $5.84^{\mathrm{ab}}$ & $4.75^{b}$ & $4.71^{b}$ & $6.48^{\mathrm{a}}$ & 0.43 & 0.03 \\
\hline VBN (mg \%) & 6.20 & 6.26 & 6.64 & 6.74 & 0.19 & 0.19 \\
\hline TBARS (mg MA/kg) & $0.34^{b}$ & $0.33^{b}$ & $0.49^{\mathrm{a}}$ & $0.47^{\mathrm{ab}}$ & 0.04 & 0.03 \\
\hline Hardness (kg) & 7.47 & 5.86 & 6.12 & 6.65 & 0.41 & 0.07 \\
\hline Springiness & 0.52 & 0.50 & 0.50 & 0.52 & 0.01 & 0.41 \\
\hline Cohesiveness & $0.43^{\mathrm{ab}}$ & $0.38^{b}$ & $0.43^{\mathrm{ab}}$ & $0.46^{\mathrm{a}}$ & 0.02 & 0.05 \\
\hline Gumminess & $3.27^{\mathrm{a}}$ & $2.24^{b}$ & $2.62^{\mathrm{ab}}$ & $3.05^{\mathrm{a}}$ & 0.22 & 0.02 \\
\hline Chewiness (kg) & $1.67^{\mathrm{a}}$ & $1.11^{\mathrm{b}}$ & $1.32^{\mathrm{ab}}$ & $1.62^{\mathrm{a}}$ & 0.12 & 0.01 \\
\hline Resilience (mm) & $0.24^{\mathrm{a}}$ & $0.20^{b}$ & $0.22^{\mathrm{ab}}$ & $0.23^{\mathrm{a}}$ & 0.01 & 0.01 \\
\hline
\end{tabular}

SEM, standard error of mean; CIE, Commission Internationale de l'Eclairage; WHC, water holding capacity; WBSF, Warner-Bratzler shear force; VBN, volatile basic nitrogen; TBARS, 2-Thiobarbituric acid reactive substances.

a,b Mean values followed by different letters in the same row are significantly different $(p<0.05)$.

etary level of tapioca increased, in agreement with the results of the present study.

In addition, the results of the present study show that as the dietary level of tapioca residue increased, feed intake tended to decrease slightly. However, tapioca residue did not affect $\mathrm{ADG}$ and FCR. This finding is in agreement with the findings of other studies, which have also reported that the digestibility of tapioca is comparable to corn flakes $[7,15]$.

We found no effects of supplementation with tapioca residue on ADG and FCR in late fattening Hanwoo steers. Likewise, previous studies have shown that substituting corn, barley, and sorghum with tapioca did not affect the ADG or FCR of beef cattle $[7,15]$.

However, our results differ from previous studies, which found that the substitution of corn and barley with tapioca residue enhanced productivity measures such as ADG and FCR in buffalo calves [16] and dairy cattle [17]. The differences observed between studies could be explained by differences in the types of experimental diets, as well as the quality and processing methods of the tapioca residue. Furthermore, Adebowale et al [18] found that the chemical composition of tapioca varied as a result of both genetic variation and processing (roasting) methods. They also reported that the dietary composition of tapioca was $7.20 \%$ to $10.50 \%$ moisture, $1.88 \%$ to $2.75 \%$ sugar, $86.96 \%$ to $94.75 \%$ starch, $89.79 \%$ to $97.34 \%$ carbohydrate, $0.23 \%$ to $0.26 \%$ protein, and $0.12 \%$ to $0.25 \%$ fat.
The concentration of plasma cholesterol in beef cattle is generally correlated with the fat content (degree of marbling) of the carcass, and thus the high concentration of plasma cholesterol in the T6.7 group (6.7\% tapioca residue) directly affected the marbling score (Table 5). Wheeler et al [19] reported that the concentration of serum cholesterol in crossbred species with higher contents of carcass fat was higher than that of Chianina species, and that the carcass fat and lipid contents of the longissimus muscle were correlated with the concentration of serum cholesterol (values of 0.71 and 0.63 , respectively). In addition, the concentration of plasma cholesterol was higher in the T6.7 group, which also had a slightly higher feed energy (total digestible nutrients [TDN] and ether extract) than the other treatment groups. This finding is similar to the finding of Arave et al [20], who reported that serum cholesterol concentrations increased as energy intake increased.

The concentration of plasma NEFA has been used as an indicator of nutritional status and energy balance and has been reported to increase when either feed intake is reduced or energy is lacking [21]. In the present study, the NEFA concentration was higher in the T9 and T12 groups than in the T6.7 group, which may be related to the decrease in feed intake observed at the higher levels of tapioca residue supplementation (Table 2). The low NEFA concentration observed in the T6.7 group suggests the inhibition of body fat degradation [22] and the effective synthesis of fatty acids from NEFA (a precursor of lipid synthesis) by insulin. In addition, it is 
possible that low NEFA-likely owing to lipid synthesis by insulin is related to the high marbling score observed in the T6.7 group (Table 5).

Blood corpuscle parameters (e.g., WBC, RBC, HGB, HCT, $\mathrm{MCV}$, and $\mathrm{MCH}$ ) are the main blood components of hematopoiesis, and are important in the diagnosis, treatment, and assessment of the physiological status of ruminants [23]. We found no differences in blood corpuscle parameters between the treatment groups supplemented with tapioca residue, and all parameters were within their normal ranges.

\section{Carcass characteristics and meat composition of the longissimus muscle}

In the present study, supplementation with tapioca residue had little effect on the back fat thickness, rib eye area, and marbling scores of Hanwoo steers. This may be owing to similar levels of feed intake and ADG values (Table 2), which reflect the similar energy (TDN) and crude protein contents (Table 1) of concentrates between the treatments.

The Korea Institute for Animal Products Quality Evaluation (KAPE) [24] reported that a total of 2,022,791 Hanwoo steers were slaughtered from 2012 to 2016 in Korea, and that the average carcass weight, back fat thickness, rib eye area, and marbling scores were $425.8 \mathrm{~kg}, 13.2 \mathrm{~mm}, 90.4 \mathrm{~cm}^{2}$, and 5.5 , respectively. The results of KAPE are different from the results of the present study, which may be a result of differences in the castration and slaughter ages. In most Hanwoo farms in Korea, calves are castrated at 6 to 8 months of age and are slaughtered at 31 to 32 months of age. However, in the present study, the castration and slaughter ages were 14 and 30 months, respectively. Because of the delayed castration age and younger slaughter age in our study, marbling scores were slightly lower; however, carcass weights and rib-eye areas were higher in comparison to the average results reported by KAPE [24].

Lee et al [25] reported that moisture and ether extract contents were influenced by the proportion of marbling. In the present study, ether extract contents in the longissimus muscle tended to be higher in the T6.7 group, which also exhibited higher marbling. This finding is concurrent with that of Chin et al [26], who found that the contents of ether extract were increased in proportion to marbling.

Wulf and Page [27] reported that the normal $\mathrm{pH}$ of beef is less than 5.75. In the present study, the $\mathrm{pH}$ of the longissimus muscle was normal in all treatments, indicating that supplementation with tapioca residue had no effect on the $\mathrm{pH}$ of the longissimus muscle.

In addition to marbling, meat color is an important factor in meat quality grading and consumer preferences, and it has been reported that brightness, redness, and yellowness all increased in proportion to marbling [25]. In agreement with previously reported results, the lightness, redness, and yellow- ness of meat were higher in the T6.7 group the present study, which is related to the higher degree of marbling observed in this group. However, redness and yellowness tended to be lower in the T9 and T12 groups in comparison to T0 (0\% tapioca residue), despite the differences in the marbling score. This finding may be a result of the decreased proportion of corn, which contains carotenoid-type pigments such as chlorophyll or xanthophyll [28].

In the present study, the WHC of longissimus muscle was not affected by the different marbling scores, which are also related to tapioca supplementation levels. This is similar to the findings of Lee et al [29] and Chin et al [26], wherein the marbling scores and the quality grades of meat did not affect water holding capacity.

We found that the shear force and other physical properties (elasticity, cohesiveness, stickiness, and chewiness) of the longissimus muscle tended to be lower as supplementation with tapioca residue increased, which was also related to the observed increase in marbling scores. Lee et al [29] reported that the shear force decreased significantly from 8.29 to 2.83 $\mathrm{kg}$ as meat grade increased from 3 to $1^{++}$, while the results of other previous studies [30,31] are also in agreement with the results of the present study.

In conclusion, supplementing the diets of Hanwoo steers with tapioca residue had no negative effects on growth performance, carcass characteristics, and meat composition. However, as the dietary level of tapioca residue increased, the concentrate intake decreased, and thus supplementing diets with more than $6.7 \%$ tapioca hardly improved the marbling score.

\section{CONFLICT OF INTEREST}

We certify that there is no conflict of interest with any financial organization regarding the material discussed in the manuscript. Park BK, Lee DK, Park JK are employees of Nonghyup Feed Co., LTD.

\section{ACKNOWLEDGMENTS}

This research was supported by the "RDA Research Associate Fellowship Program" of the National Institute of Animal Science, Rural Development Administration, Korea

\section{REFERENCES}

1. Ministry of Agriculture, Food and Rural Affairs. 2016. Agriculture, food and rural affairs statistics yearbook. Sejong, Korea: MAFRA; 2016.

2. Chanjula P, Ngampongsai W, Wanapat, $M$. Effects of replacing ground corn with cassava chip in concentrate on feed intake, nutrient utilization, rumen fermentation characteristics and microbial populations in goats. Asian-Australas J Anim Sci 
2007;20:1557-66. https://doi.org/10.5713/ajas.2007.1557

3. Irekhore OT, Bamgbose AM, Olubadewa GA. Utilization of cassava peel meal as energy source for growing pigs. J Anim Vet Adv 2006;5:849-51.

4. Enriquez FQ, Ross E. Cassava root meal in grower and layer diets. Poult Sci 1972;51:228-32. https://doi.org/10.3382/ps. 0510228

5. Vearsilp T, Mikled C. Site and extent of cassava starch digestion in ruminants. In: International Workshop on Current Research and Development on Use of Cassava as Animal Feed. Khon kaen, Thailand: Khon Kaen University; 2001.

6. Muller Z, Chou KC, Nah KC. Cassava as a total substitute for cereals in livestock and poultry rations. In: Proceedings of the 1974 Tropical Products Institute Conference; 1975 April 1-5: London, UK. Tropical Products Institute Conference; 1975. pp. 85-95.

7. Zinn RA, DePeters EJ. Comparative feeding value of tapioca pellets for feedlot cattle. J Anim Sci 1991;69:4726-33.

8. Association of Official Analytical Chemists. Official methods of analysis. 15th ed. Washington, DC, USA: AOAC International; 1995.

9. Ministry of Agriculture, Food and Rural Affairs [MAFRA]. 2017 Grade rule for cattle carcass in Korea. Sejong, Korea: Korea Ministry of Government Legislation [cited 2017 Nov 30]. Available from: http://www.law.go.kr/main.htm

10. Hofmann AW, White WM. Mantle plumes from ancient oceanic crust. Earth Planet Sci Lett 1982;57:421-36. https://doi.org/10. 1016/0012-821X(82)90161-3

11. Kim D, Gil J, Kim HJ, et al. Changes in meat quality and natural di-peptides in the loin and ham cuts of Korean native black pigs during cold storage. Korean J Life Sci 2013;23:1477-85. https://doi.org/10.5352/JLS.2013.23.12.1477

12. Witte VC, Krause GF, Bailey ME. A new extraction method for determining 2-thiobarbituric acid values of pork and beef during storage. J Food Sci 1970;35:582-5. https://doi.org/10. 1111/j.1365-2621.1970.tb04815.x

13. SAS Institute Inc. SAS 9.1.3. SAS Institute Inc., Cary, NC, USA; 2005.

14. Garcia M, Dale N. Cassava root meal for poultry. J Appl Poult Res 1999;8:132-7. https://doi.org/10.1093/japr/8.1.132

15. Holzer Z, Aharoni Y, Lubimov V, Brosh A. The feasibility of replacement of grain by tapioca in diets for growing-fattening cattle. Anim Feed Sci Technol 1997;64:133-41. https://doi.org/ 10.1016/S0377-8401(96)01054-1

16. Etman KEI, Soliman IM, Abou-Selim IAS, Soliman AA. Cassava (Manihot esculenta, crantz.) in rations of buffaloes: E. Effect of partial replacement of yellow corn by cassava pellets in rations of growing buffaloes calves. Prospects of buffalo production in the Mediterranean and the Middle East. Pudoc Scientific Publishers, Cairo, Egypt. Wageningen; 1993.

17. Sommart K, Wanapat M, Rowlinson P, Parker DS, Climee P, Panishying $\mathrm{S}$. The use of cassava chips as an energy source for lactating dairy cows fed with rice straw. Asian-Australas J Anim Sci 2000;13:1094-101. https://doi.org/10.5713/ajas.2000.1094

18. Adebowale AA, Sanni LO, Onitilo, MO. Chemical composition and pasting properties of tapioca grits from different cassava varieties and roasting methods. Afr J Food Sci 2008;2:77-82.

19. Wheeler TL, Davis GW, Stoecker BJ, Harmon CJ. Cholesterol concentration of longissimus muscle, subcutaneous fat and serum of two beef cattle breed types. J Anim Sci 1987;65:15317. https://doi.org/10.2527/jas1987.6561531x

20. Arave CW, Miller RH, Lamb RC. Genetic and environmental effects on serum cholesterol of dairy cattle of various ages. J Dairy Sci 1975;58:423-7. https://doi.org/10.3168/jds.S00220302(75)84582-6

21. Beever DE. The impact of controlled nutrition during the dry period on dairy cow health, fertility and performance. Anim Reprod Sci 2006;96:212-26. https://doi.org/10.1016/ j.anireprosci.2006.08.002

22. Lafontan M. Inhibition of epinephrine-induced lipolysis in isolated white adipocytes of aging rabbits by increased alphaadrenergic responsiveness. J Lipid Res 1979;20:208-16.

23. Cho HU. Hematological and biochemical analysis of Korean indigenous cattle according to the ages [master's thesis]. Jeonju, Korea: Chonbuk National University; 2010

24. Korea Institute for Animal Products Quality Evaluation. 2017 Animal Products Grading Statistical Yearbook. Sejong, Korea: Korea Institute for Animal Products Quality Evaluation; 2017. Report No.: 11-B552679-000006-10

25. Lee JM, Park BY, Cho SH, et al. Analysis of carcass quality grade components and chemicophysical and sensory traits of M. longissimus dorsi in Hanwoo. J Anim Sci Technol 2004;46: 833-40. https://doi.org/10.5187/JAST.2004.46.5.833

26. Chin KB, Go MY, Lee HC, Chung SK, Baik KH, Choi CB. Physicochemical properties and tenderness of Hanwoo loin and round as affected by raising period and marbling score. Korean J Food Sci An 2012:32:842-8. https://doi.org/10.5851/ kosfa.2012.32.6.842

27. Wulf DM, Page JK. Using measurements of muscle color, $\mathrm{pH}$, and electrical impedance to augment the current USDA beef quality grading standards and improve the accuracy and precision of sorting carcasses into palatability groups. J Anim Sci 2000;78:2595-607. https://doi.org/10.2527/2000.78102595x

28. Chang J, Hansen MC, Pittman K, Carroll M, DiMiceli C. Corn and soybean mapping in the United States using MODIS timeseries data sets. Agron J 2007;99:1654-64.

29. Lee JM, Choe JH, Lee HK, et al. Effect of quality grades on carcass characteristics, physico-chemical and sensory traits of longissimus dorsi in Hanwoo. Korean J Food Sci An 2010; 30:495-503. https://doi.org/10.5851/kosfa.2010.30.3.495

30. Laster MA, Smith RD, Nicholson KL, et al. Dry versus wet aging of beef: Retail cutting yields and consumer sensory attribute evaluations of steaks from rib eyes, strip loins, and top sirloins from two quality grade groups. Meat Sci 2008;80:795-804. https:// 
doi.org/10.1016/j.meatsci.2008.03.024

31. Obuz E, Dikeman ME, Grobbel JP, Stephens JW, Loughin TM. Beef longissimus lumborum, biceps femoris, and deep pectoralis
Warner-Bratzler shear force is affected differently by endpoint temperature, cooking method, and USDA quality grade. Meat Sci 2004;68:243-8. https://doi.org/10.1016/j.meatsci.2004.03.003 